\title{
Catabolism of hydroxyacids and biotechnological production of lactones by Yarrowia lipolytica
}

Received: 26 August 2002 / Revised: 21 November 2002 / Accepted: 22 November 2002 / Published online: 28 January 2003 (C) Springer-Verlag 2003

\begin{abstract}
The $\gamma$ - and $\delta$-lactones of less than 12 carbons constitute a group of compounds of great interest to the flavour industry. It is possible to produce some of these lactones through biotechnology. For instance, $\gamma$-decalactone can be obtained by biotransformation of methyl ricinoleate. Among the organisms used for this bioproduction, Yarrowia lipolytica is a yeast of choice. It is well adapted to growth on hydrophobic substrates, thanks to its efficient and numerous lipases, cytochrome P450, acylCoA oxidases and its ability to produce biosurfactants. Furthermore, genetic tools have been developed for its study. This review deals with the production of lactones by $Y$. lipolytica with special emphasis on the biotransformation of methyl ricinoleate to $\gamma$-decalactone. When appropriate, information from the lipid metabolism of other yeast species is presented.
\end{abstract}

\section{Introduction}

The possibility of producing a lactone in a biotechnological way was discovered in the 1960s when the group of Okui (Okui et al. 1963a, 1963b, 1963c; Uchimaya et al. 1963) was studying the catabolism of hydroxyacids in various organisms. Although the animal cells and bacteria studied degraded ricinoleic acid to $\mathrm{C} 16, \mathrm{C} 14$ and $\mathrm{C} 12$ hydroxy acids, the yeast Candida tropicalis accumulated $\gamma$-decalactone, a lactone exhibiting fruity and oily notes important in the formulation of peach, apricot or strawberry aromas.

\footnotetext{
Y. Waché $(\bullet) \cdot$ M. Aguedo · J.-M. Belin Laboratoire de Microbiologie, UMR UB/INRA 1082, ENSBANA, 1 Esplanade Erasme, 21000 Dijon, France e-mail: ywache@u-bourgogne.fr

Tel.: +33-03-80396680

Fax: +33-03-80396641

J.-M. Nicaud

Laboratoire de Génétique des Micro-Organismes, INRA-CNRS, URA1925,

Thiverval-Grignon, France
}

Since this observation, biotechnologists have devoted their efforts to the selection of yeast strains able to produce high amounts of lactones.

The yeast Yarrowia lipolytica, which is particularly adapted to hydrophobic environments (Barth and Gaillardin 1996, 1997), has been successfully tested. The fact that there are genetic tools adapted to the study of this organism has helped this species to become a reference in research dealing with non-polar substrate metabolism. In the field of lipid-derived aroma compounds, the importance of $Y$. lipolytica is also high, as acknowledged by the many patents and papers mentioning it.

$\gamma$-Decalactone is one of the most produced lactones. Its production through biotechnology results in a natural lactone. The annual market for $\gamma$-decalactone has been growing in recent years and was estimated in 1997 at about $10 \mathrm{t}$ (Gatfield 1999). This high production resulted in a sharp decrease in prices: from U.S. $\$ 12,000 / \mathrm{kg}$ in 1986 , the price declined to U.S. \$ 500/kg in 1998 (Gatfield 1999). As a consequence, companies who just required a simple production process some years ago are getting more and more interested in lowering the manufacturing costs. As a result, research on this subject, which was mainly devoted to the screening of strains or conditions, is now getting closer to the biological mechanisms of the catabolism of hydroxyacids to such an extent that this very applied field now generates a nonnegligible amount of basic results concerning yeast lipid metabolism.

In this Mini-Review, we present the production of lactones for which $Y$. lipolytica is employed; and the biological pathway to obtain $\gamma$-decalactone is described in detail. In the first part, processes are presented and the metabolic pathways for $\gamma$-decalactone production from methyl ricinoleate (or ricinoleic acid) are described. Then, some current fields of investigation are presented, such as the optimisation of production through the study of $\beta$ oxidation fluxes, better knowledge of lactone toxicity towards the producing yeast and preliminary results regarding the yeast surface properties to facilitate substrate uptake. 
Table 1 Structure, name and odorous properties of the lactones that can be produced by the yeast Yarrowia lipolytica

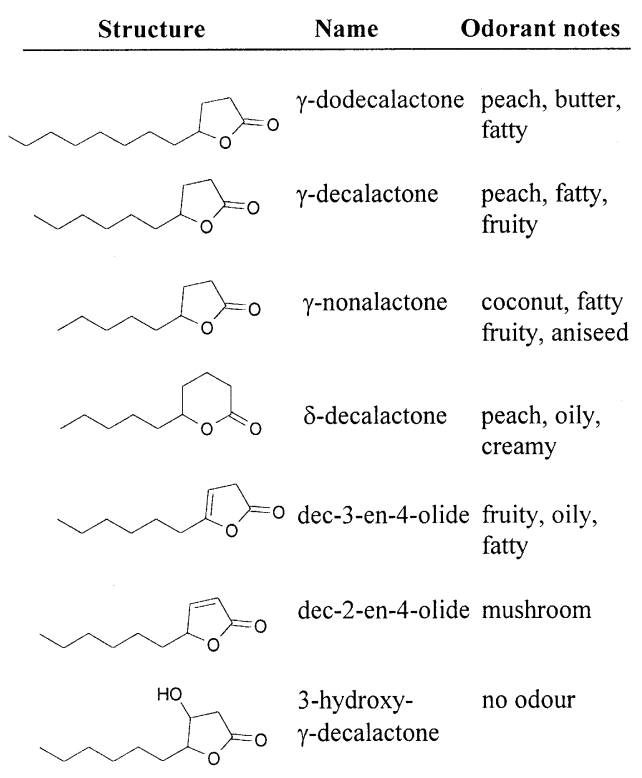

\section{Production of lactones by biotransformation}

$\gamma$ - and $\delta$-lactones (4- and 5-alkanolides) with odorous properties are naturally present in fruit and in some fermented food products (Tang and Jennings 1968; Maga 1976). These aroma compounds possess varied sensory properties with mainly fruity and fatty characteristics (Table 1), which make them interesting food additives. The flavour of lactones is influenced by the lactone cycle structure, the length of the lateral carbon chain, the presence of unsaturations and chirality (Maga 1976; Dufossé et al. 1993). Some fungi (Collins and Halim 1972; Sarris and Latrasse 1985; Berger et al. 1986) and some yeast species (Tahara et al. 1972) were first identified for their ability to produce small amounts of aroma compounds by de novo synthesis. As their extraction from fruits was not financially viable, this production by micro-organisms was progressively optimised, giving rise to industrial applications that enabled researchers to obtain lactones with a "natural" label at economically viable costs. The patents mentioning $Y$. lipolytica for the production of lactones are presented in Table 2. For instance $\gamma$-decalactone, which is currently one of the main products derived from aroma biotechnology, is generally obtained by biotransformation of a

Table 2 Processes of production of lactones mentioning Y. (Candida) lipolytica

\begin{tabular}{|c|c|c|c|c|c|}
\hline Species or strain & Substrate & Products & Yield & Description & $\begin{array}{l}\text { Reference (and } \\
\text { organisation) }\end{array}$ \\
\hline $\begin{array}{l}\text { Y. lipolytica, Aspergillus } \\
\text { orizae, G. klebahnii and } \\
\text { many Candida spp }\end{array}$ & $\begin{array}{l}\text { Castor oil, castor } \\
\text { oil + lipase, castor } \\
\text { oil hydrolysate }\end{array}$ & $\gamma$-Decalactone & $\begin{array}{l}0.69 \mathrm{~g} / \mathrm{l} \text { in } \\
\text { up to } 1 \text { week }\end{array}$ & Agitated flasks & $\begin{array}{l}\text { Farbood and Willis } \\
\text { (1983) } \\
\text { (F. Dodge and Olcott) }\end{array}$ \\
\hline Candida spp & $\begin{array}{l}\text { Castor oil, } \\
\text { ricinoleic acid }\end{array}$ & $\begin{array}{l}\text { Unsaturated } \\
\text { lactones }\end{array}$ & $\begin{array}{l}\text { High aeration } \\
\text { and agitation }\end{array}$ & & $\begin{array}{l}\text { Farbood et al. (1990) } \\
\text { (IFF) }\end{array}$ \\
\hline $\begin{array}{l}Y . \text { lipolytica, Aspergillus } \\
\text { orizae, G. klebahnii } \\
\text { and } H . \text { saturnus }\end{array}$ & Ricinoleic esters & $\gamma$-Decalactone & $\begin{array}{l}5.1 \mathrm{~g} / 1 \\
\text { after } 70 \mathrm{~h}\end{array}$ & $\begin{array}{l}\text { Lactonisation at } \\
60-120{ }^{\circ} \mathrm{C} \text { and } \mathrm{pH} 2\end{array}$ & Meyer (1993) (BASF) \\
\hline $\begin{array}{l}\text { Yarrowia and Candida } \\
\text { spp }\end{array}$ & $\begin{array}{l}\text { 10-OH-stearic acid, } \\
\text { Oleic acid }\end{array}$ & $\begin{array}{l}\gamma \text {-Dodecalactone, } \\
\text { unsaturated lactones }\end{array}$ & $3.5 \mathrm{~g} / 1$ & $\begin{array}{l}\text { Hydroxylated } \\
\text { (Pseudomonas spp) } \\
\text { C18 fatty acids }\end{array}$ & $\begin{array}{l}\text { Farbood et al. (1994) } \\
\text { (IFF) }\end{array}$ \\
\hline $\begin{array}{l}\text { Sporobolomyces and } \\
\text { Yarrowia }\end{array}$ & $\begin{array}{l}\text { Residue derived } \\
\text { from the distillation } \\
\text { of fermentation } \\
\text { products (cognac) }\end{array}$ & $\begin{array}{l}\gamma \text {-Decalactone and } \\
\text { other products }\end{array}$ & & $\begin{array}{l}\text { Methyl ricinoleate } \\
\text { is added as the } \\
\text { precursor }\end{array}$ & Ambid et al.(1999) \\
\hline $\begin{array}{l}\text { Y. lipolytica HR145 } \\
\text { (DSM12397) }\end{array}$ & Castor oil & $\begin{array}{l}\gamma \text {-Decalactone, } \\
\text { hydroxylactone }\end{array}$ & $\begin{array}{l}11 \mathrm{~g} / 1 \text { in less } \\
\text { than } 70 \mathrm{~h}\end{array}$ & One-step reaction & $\begin{array}{l}\text { Rabenhorst and } \\
\text { Gatfield (2000) } \\
\text { (Haarmann } \\
\text { and Reimer) }\end{array}$ \\
\hline $\begin{array}{l}\text { Saccharomyces and } \\
\text { Candida spp }\end{array}$ & $\begin{array}{l}\text { 5-Hydroxydecanoic } \\
\text { acid }\end{array}$ & $\gamma$-Nonalactone & & $\alpha$-Oxidation & $\begin{array}{l}\text { Lange and Garbe } \\
(2000)\end{array}$ \\
\hline
\end{tabular}


long-chain hydroxy fatty acid precursor by yeast cells. Ricinoleic acid is a convenient substrate since this hydroxy acid represents almost $90 \%$ of hydrolysed castor oil. Y. lipolytica is one of the yeast species that are able to produce $\gamma$-decalactone from ricinoleic acid or its methyl ester. It was initially mentioned in a process patented by Farbood and Willis (1983) and its use for lactones production has been patented several more times, concerning the production of $\gamma$-decalactone (Cardillo et al. 1991a, 1991b; Meyer 1993; Ambid et al. 1999; Rabenhorst and Gatfield 2000). As for the utilisation of other yeast species, the processes often lead to the production of the direct precursor of $\gamma$-decalactone, i.e. 4-hydroxydecanoic acid, which is then spontaneously lactonised under acid conditions (Meyer 1993; Dufossé 1993). All these processes report the production of lactones by Y. lipolytica at concentrations of several grams per litre; and examples of $9.5 \mathrm{~g} / \mathrm{l}$ after $75 \mathrm{~h}$ (Nicaud et al. 1996) and $12 \mathrm{~g} / \mathrm{l}$ (Rabenhorst and Gatfield 2000) were given. In the case of Nicaud et al. (1996), an uracil auxotrophic strain (ura3; the W29 (ATCC 24060) derived strain PO1d) was transferred at high cell concentrations in a medium containing poor amounts of uracil, which only allowed a very weak yeast proliferation. $Y$. lipolytica was also reported in patents dealing with the production of some other lactone aroma compounds: $\gamma$-dodecalactone (Cardillo et al. 1991a, 1991b; Farbood et al. 1994), $\gamma$-nonalactone from 5-hydroxydecanoic acid (Lange and Garbe 2000), unsaturated lactones (Farbood et al. 1990; Cardillo et al. 1991a, 1991b; Farbood et al. 1994) and $\delta$-lactones (Cardillo et al. 1991a, 1991b).

$Y$. lipolytica has also been described for its ability to produce high amounts of some other lactones during the biotransformation of methyl ricinoleate into $\gamma$-decalactone: 3-hydroxy- $\gamma$-decalactone, dec-2-en-4-olide and dec3-en-4-olide (Gatfield et al. 1993). These three compounds, which are derived from 4-hydroxydecanoic acid (or its CoA ester; Waché et al. 2001), are currently not used by the aroma industry: in fact, the dec-3-en-4-olide has been described as possessing a fruity, peach-like odour, more powerful than that of $\gamma$-decalactone, but its potential utilisation would depend on a cheap method to separate it from its isomer (dec-2-en-4-olide), which possesses a mushroom-like note.

The lactone concentrations obtained during the processes were achieved through optimisation of the yeast culture conditions, leading very often to biotransformation yields that were rather low. Further improvements were expected to be reached from the knowledge of the metabolic pathways leading to the bioproduction of the lactones; and these have been progressively elucidated.

\section{Biological pathway}

We focus here on the biological pathway from methyl ricinoleate to $\gamma$-decalactone, the main lactone produced by $Y$. lipolytica.
Although the implication of $\beta$-oxidation in this biotransformation pathway has been hypothesised from the first study (Okui et al. 1963b), many obscure points remain, corresponding to subjects of yeast lipid metabolism, which has been less studied. In particular, the entry of the substrate into the peroxisome, some aspects of the $\beta$-oxidation reactions (especially those involving auxiliary enzymes and the organisation of the fluxes) and the lactonisation/way-out for the product are not well known. The various studies on the subject have been carried out in different yeast species, each enabling more or less important steps forward in the understanding of the precise pathway. When appropriate, we present in this part data from studies dealing with yeasts other than $Y$. lipolytica.

\section{Substrate entry into the cell}

First in this process, the yeast cell is in the presence of the substrate, which can be castor oil, ricinoleic acid or, more often, methyl ricinoleate. Except in the case of the free fatty acid, the substrate has thus to be hydrolysed, a step which seems to take place in the extracellular medium. It can be mentioned here that most of the lactone-producing yeasts, including $Y$. lipolytica (Pignède et al. 2000a, 2000b), possess active extracellular lipases.

The second step concerns the adsorption of the fatty acid to the yeast surface and its entry into the cell. This step is rather unknown, although interactions of fatty acids with cell walls are currently being investigated and will be discussed later. Different mechanisms of entry have been described, mostly in bacteria, involving hydrophobic interactions or surfactant-mediated phenomena. They result in a mechanism of direct interfacial or surfactant-facilitated transport (Bouchez-Naïtali et al. 1999, 2001). Some protrusion-forming structures resembling canals have been observed during the growth of $C$. tropicalis in alkane (Osumi et al. 1975; Meisel et al. 1976, 1977; Tanaka and Fukui 1989). They could constitute the transport structure but, to date, no demonstration has been proposed to explain the cell wall passage. However, the cell wall is not required in the lipid metabolism, since spheroplasts of $C$. tropicalis are able to metabolise oleic acid (Medvedeva et al. 1969) and those of Y. lipolytica are able to utilise methyl ricinoleate and to produce $\gamma$ decalactone (Aguedo et al. 2000).

The passage of fatty acids through the plasma membrane is, in all organisms, highly controversial. In yeast, investigations carried out by Kohlwein and Paltauf (1983) in Saccharomyces cerevisiae and Saccharomycopsis lipolytica (syn. Y. lipolytica) with lauric or oleic acid concluded that, beyond a threshold of $10 \mu \mathrm{M}$, an energyfree transporter was required whereas, above this concentration, the fatty acids diffused freely. 


\section{Cytoplasmic fate}

Inside the cell, fatty acids can be either stocked or utilised. Fatty acids have been shown to accumulate in different structures, described as vacuoles or spherosomes (Gill et al. 1977; Brennan and Lösel 1978). These structures seem to be in contact with some organelles favouring the accession of fatty acids to their degradation site (Brennan and Lösel 1978). Feron et al. (1997) observed in Sporidiobolus salmonicolor that, in contrast with oleic acid, ricinoleic acid accumulated inside the cells. Moreover, ricinoleic acid was metabolised more slowly than oleic acid, although the cell density was significantly higher. They explained this difference by the accumulation of $\gamma$-decalactone during metabolism of the hydroxy acid. This product would be toxic (decreasing metabolism) through its capacity for permeabilising membranes (thus increasing the accumulation of ricinoleic acid inside the cell). The accumulation of methyl ricinoleate in $Y$. lipolytica has been investigated and the results suggest that this accumulation is closely dependent on the physiological state of the cells (Aguedo 2000; Aguedo et al., unpublished results).

To be catabolised, fatty acids have to be activated in their coenzyme A ester forms. The fatty acid transport within the cytoplasm to the right enzyme has not been elucidated and the rare works dealing with fatty acidbinding proteins (FABP) in yeasts have not been successful (Scholz et al. 1990; Smaczynska et al. 1994), apart from those of Dell' Angelica et al. (1992), who identified a FABP in $Y$. lipolytica. The activation is catabolised by an acyl-CoA synthetase (ACS). In contrast to FABP, ACSs have been observed in yeast cells for years: the acyl-CoA synthetase 1 of $C$. lipolytica was characterised in 1979 (Hosaka et al. 1979). These enzymes are localised in organelles. In Pichia pastoris, the very-long-chain-specific ACS is peroxisomal and the long-chain-specific one is mitochondrial (Kalish et al. 1995) whereas, in Saccharomyces cerevisiae, there are two peroxisomal ACS, one long-chain-specific and the other very-long-chain-specific, and both can activate C18 acids (Watkins et al. 1998).

Acyl-CoA can be transported by acyl-CoA-binding proteins. These proteins, initially discovered as an impurity in a FABP preparation (Mogensen et al. 1987), constitute a family that is well conserved over all eukaryotic species (Knudsen et al. 1999). In yeast, overexpression experiments have shown its role in acylCoA pool formation (Mandrup et al. 1993; Knudsen et al. 1994); and gene disruption strongly suggests a role in transport (Schjerling et al. 1996).

\section{Transport to the peroxisomes}

Recent results (Dansen et al. 2000) and older works (Nicolay et al. 1987) agree that the peroxisome internal $\mathrm{pH}$ is different from the cytoplasmic one. This ATPasemaintained intraperoxisomal $\mathrm{pH}$ could contribute to the generation of a proton motive force (Douma et al. 1987), which could play a role in transports. The peroxisomal membrane has been shown in vitro to be permeable to small compounds (such as sucrose, $\mathrm{NAD}^{+}, \mathrm{CoA}$, ATP, carnitine) and this could be due to the presence of poreforming proteins (Van Veldhoven et al. 1987). However, more recent works suggest that, in vivo, the membrane is rather impermeable to $\mathrm{NAD}(\mathrm{H})$ and acetyl-CoA (Van Roermund et al. 1995). ATP for its part has been shown to enter the peroxisomal lumen through the action of a transporter (Palmieri et al. 2001), in the absence of which medium-chain (but not long-chain) fatty acids could not be activated into acyl-CoA (Van Roermund et al. 2001).

\section{Peroxisomal $\beta$-oxidation}

The implication of $\beta$-oxidation has been deduced from the accumulation of metabolic intermediates. The compounds detected during the pathway were first those accumulating between two $\beta$-oxidation loops (Okui et al. 1963a), excluding the 4-hydroxydecanoic acid which was probably lactonising spontaneously before detection, as reported for other 4-hydroxy acids (Fantin et al. 2001). This very unstable acid was later detected (Feron et al. 1996) and the detection of other intermediates was improved with the use of biphasic media (Spinnler et al. 1996) or by processing the pathway in vitro (Blin-Perrin et al. 2000).

Apart from rare and older studies mentioning acylCoA dehydrogenase activities (Haffner and Tressl 1996) or other characteristics that are specific to mitochondrial $\beta$-oxidation (Blin-Perrin et al. 2000), this pathway is, in yeast, generally considered as being peroxisomal. $\beta$ Oxidation is a four-reaction sequence resulting in a twocarbon chain-shortening catalysed in peroxisomes by the following activities: acyl-CoA oxidase, 2-enoyl-CoA hydratase, 3-hydroxyacyl-CoA dehydrogenase and 3ketoacyl-CoA thiolase (Fig. 1). The commonly accepted pathway from ricinoleyl-CoA to $\gamma$-decalactone is presented in Fig. 2: four $\beta$-oxidation cycles occur, yielding 4hydroxy-decanoyl-CoA, which is then, after some still unknown steps, cyclised to $\gamma$-decalactone.

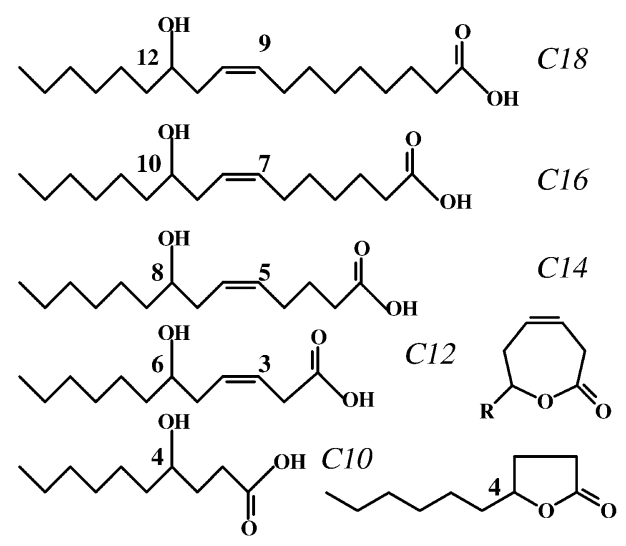

Fig. 1 Intermediates detected during the degradation of ricinoleic acid. $R: \mathrm{C}_{6} \mathrm{H}_{13}$ 


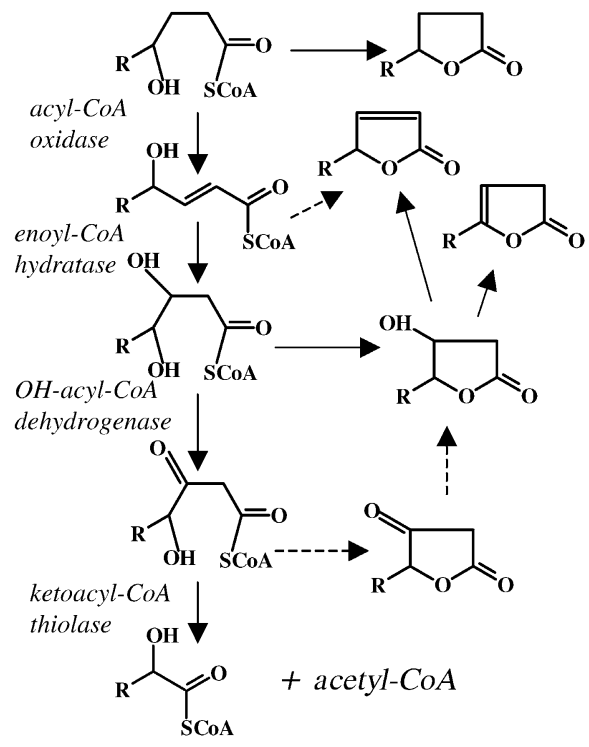

Fig. 2 The four steps of $\beta$-oxidation and the catalysing enzymes involved. The substrate example given for this $\beta$-oxidation loop is 4-hydroxydecanoyl-CoA, the C10 intermediate of the $\beta$-oxidation of ricinoleyl-CoA. The lactones potentially formed at each step are shown. $R: \mathrm{C}_{6} \mathrm{H}_{13}$

In $Y$. lipolytica, works dealing with the enzymes of $\beta$ oxidation have been carried out in our laboratories since the mid-1990s. This species possesses a family of five acyl-CoA oxidases (Aox1-5, encoded by POX1-5). Interest in this enzyme family came from our first experiments: disruption of poxl resulted in an increased $\beta$-oxidation activity but a decreased production of $\gamma$ decalactone, whereas overexpression of the thiolase did not modify the production (Pagot et al. 1998). Since then, the Aox family has been better characterised, using functional genetics (Waché et al. 1998; Wang et al. 1998; 1999a, 1999b, 2000). This enabled us to show that two Aox exhibited a high activity and a chain-length specificity, one being long-chain-specific (Aox2) and the other short-chain-specific (Aox3). The role of the other Aox was less evident, as Aox 4 and Aox 5 exhibited a weak activity on the whole spectrum of straight-chain acyl-CoA (from $\mathrm{C} 4$ to $\mathrm{C} 18$ ) and Aox 1 did not exhibit any detectable activity. The disruption of the genes corresponding to these three Aox resulted in a 2- to 5-fold increase in the global Aox activity, suggesting a role in the regulation of their activity. The substrate specificity of Aox 2 and Aox 3 was later confirmed with the purified enzymes (Luo et al. 2000). Furthermore, Titorenko et al. (2002) showed that the global acyl-CoA oxidase was targeted to the peroxisomes as a heteropentamer containing each Aox.

Our investigations into lactone production by $P O X$ mutants suggested strongly that the short-chain-specific Aox was involved in the continuation of the $\beta$-oxidation flux beyond the decanoyl-CoA (the $\gamma$-decalactone precursor) level and/or in the degradation of newly synthesised lactone (Waché et al. 1998, 2000a).
What happens to the double-bond of ricinoleic acid during its $\beta$-oxidation is not surely known in $Y$. lipolytica. Data concerning this metabolism by the auxiliary enzymes of $\beta$-oxidation have been obtained from other yeasts. From the enzymes present in S. cerevisiae, Gurvitz et al. (1999) proposed three different possible pathways for enoyl-CoA possessing odd-double-bonds, an isomerase-dependent one (observed in the degradation of oleic acid) and two postulated di-isomerase pathways, including one involving a reductase activity (Fig. 3). This reductase pathway was observed in the degradation of ricinoleic acid by Sporobolomyces odorus (Haffner and Tressl 1996), whereas a 3-cis, 5-cis intermediate was isolated by Iacazio et al. (Iacazio et al. 2002) during the degradation of ricinoleic acid by $P$. guilliermondii. This suggests that at least four pathways are possible to resolve the odd-double-bond problem and that there is a certain diversity between yeast species. However, the observation by Gatfield et al. (1993) of dodec-3-en-6-olide accumulation during the degradation of ricinoleic acid by $Y$. lipolytica suggests that the pathway in this species goes through a dodec-3-enoyl-CoA intermediate, a compound that is present in the isomerase-dependent pathway.

Another problem concerns the stereochemistry of the carbon carrying the hydroxy group of ricinoleic acid $(R)$ which later becomes the asymmetric carbon of the lactone. In $Y$. lipolytica, the resulting lactone has been described as being 98\% (R) (Gatfield 1999), which corresponds to the results obtained with other yeasts, such as Sporobolomyces (Haffner and Tressl 1996; Dufossé et al. 1997). We can however mention that the stereochemistry of the lactone-generating reactions is an intrinsic parameter for each species. Ercoli et al. (1992) thus observed, when growing $Y$. lipolytica or P. ohmeri on the same racemic hydroxy acids, that the two species produced the opposite enantiomers.

The yeast $Y$. lipolytica accumulates other C10-lactones in the medium (Gatfield et al. 1993; Waché et al. 2001; Fig. 1). This point is relatively original, since the presence of these lactones has only rarely been reported with other yeasts (Farbood et al. 1990). The accumulation of dec-2en-4-olide, dec-3-en-4-olide and 3-hydroxy- $\gamma$-decalactone in $Y$. lipolytica culture media was first reported by the company Haarmann and Reimer in 1993 (Gatfield et al. 1993). As presented in Fig. 2, these lactones seem to appear following lactonisation of $\beta$-oxidation intermediates at the various steps of the C10- $\beta$-oxidation cycle. Their structure is closely related to that of $\gamma$-decalactone, but their sensorial properties are quite different, as mentioned above.

The role of carnitine in yeast lipid metabolism is not completely established. Carnitine seems to be involved in the utilisation of acetyl units after peroxisomal $\beta$-oxidation. In $C$. lipolytica and Saccharomyces cerevisiae, there are a mitochondrial and a peroxisomal carnitine acyltransferase (CAT) which are both encoded by the same gene, which possesses two different targeting sequences: an internal peroxisomal one and a C-terminal mitochondrial one (Elgersma et al. 1995). Although the role of 
di-isomerase-dependent pathways ${ }^{2}$

(postulated in S. cerevisiae)

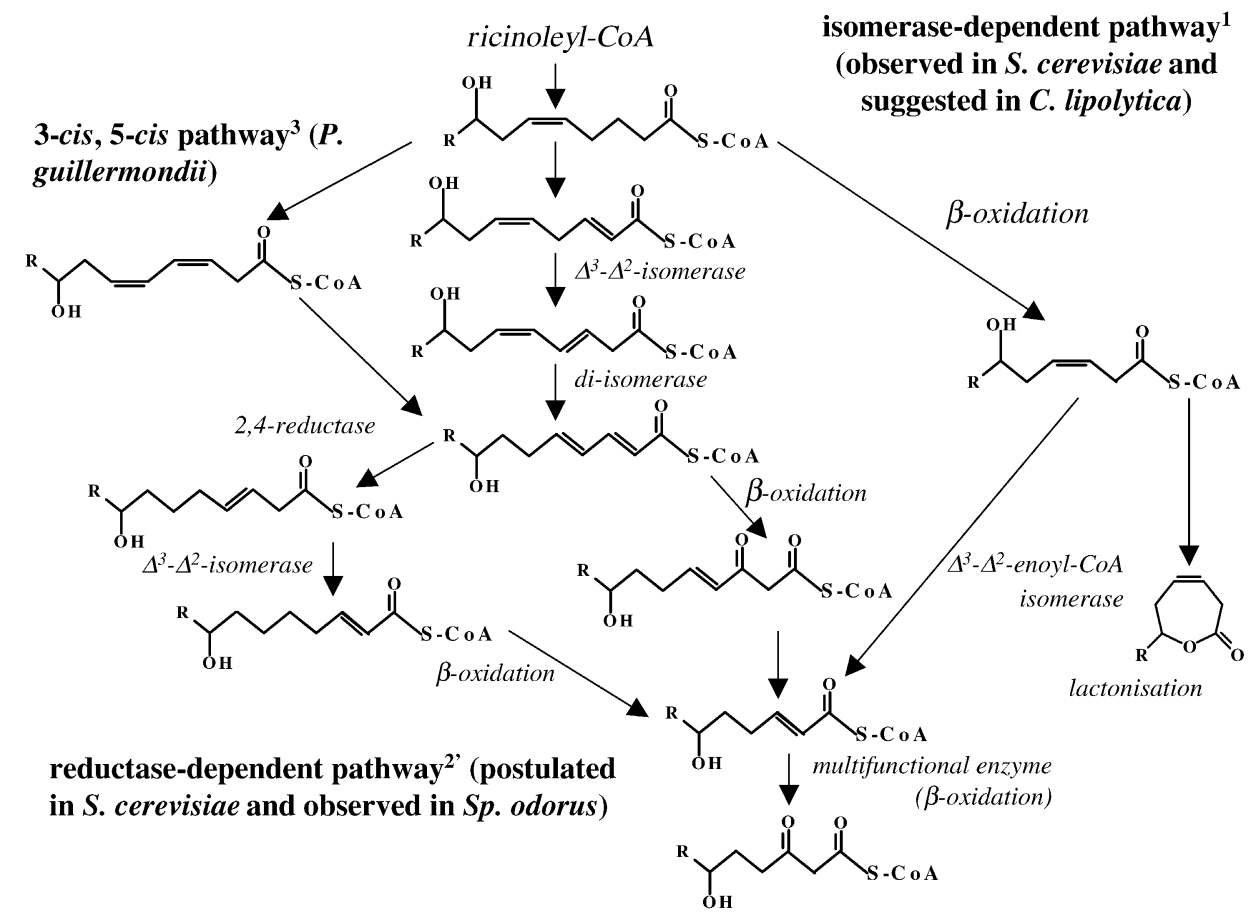

Fig. 3 Different pathways proposed for the $\beta$-oxidation of ricinoleyl-CoA. Superscript numbers refer to the following pathways: Pathway 1 The isomerase-dependent pathway is required for growth of Saccharomyces cerevisiae on oleic acid (Gurvitz et al. 1999) and was suggested, after the identification of dodec-2-en-6olide, for the degradation of ricinoleic acid by Yarrowia lipolytica (Gatfield et al. 1993). Pathway 2 From the two di-isomerase dependent pathways postulated for the degradation of oleic acid by

CAT in the peroxisomal metabolism is not well defined, the inhibition of this enzyme in $P$. guilliermondi decreases significantly the transformation of methyl ricinoleate to $\gamma$-decalactone (Pagot 1997; Pagot and Belin 1996a, 1996b).

The end of the pathway is still confused. Whether lactonisation occurs on acyl-CoA esters or on the corresponding fatty acid is not known. The second possibility is more often suggested, as many studies observed the presence of the precursor hydroxy acid in the medium (Okui et al. 1963b; Farbood and Willis 1983; Cardillo et al. 1991b; Endrizzi et al. 1993; Endrizzi and Belin 1995). In this case, lactonisation occurs outside the cell, within the culture medium.

\section{Lactone degradation}

An important point to mention in the process of lactone production is the degradation of newly synthesised lactone by the producing yeast. This phenomenon was reported as early as in the experiments of Okui et al. (1963a) with a Candida sp. and has been observed in most works since then. This point was discussed in the review
S. cerevisiae (Gurvitz et al. 1999), this reductase-dependent pathway was proposed for the degradation of ricinoleic acid by Sporobolomyces odorus (Haffner and Tressl 1996). Pathway 3 The 3-cis, 5-cis pathway was suggested recently after the identification of 8-hydroxy-3-cis, 5-cis-tetradecadienoic acid during growth of Pichia guilliermondii on ricinoleic acid (Iacazio et al. 2002) $R$ : $\mathrm{C}_{6} \mathrm{H}_{13}$

by Endrizzi et al. (1996) and we present here just the main facts and recent results.

Although the metabolic pathways of lactone degradation are not fully elucidated, we can mention here some aspects related to this degradation. First, the hydroxy acid form (unlactonised form) appears to be degraded faster than the lactone form (Endrizzi and Belin 1995). This suggests that the step of hydrolysis of the lactone exhibits a high control on the degradation. Then, the specificity of the degradation pathway is high, as degradation resolves the racemic (Fuganti et al. 1993; Latrasse et al. 1993; Fantin et al. 2001) and no degradation has been observed in the same conditions for closely related lactones, such as hydroxy- $\gamma$-decalactone or decen-4-olides (Waché et al. 2001).

Several pathways of degradation are possible. The most probable one, which has already been described in animal cells (Adams et al. 1998), includes the opening of the cycle (through a blood $\gamma$-lactonase activity in animal cells (Fishbein and Bessman 1966), activation to CoA esters and $\beta$-oxidation. When the hydroxy group is in the $\alpha$-position, an $\alpha$-decarboxylation will also be required and then $\beta$-oxidation (Voet and Voet 1990). Another possible pathway involves the $\omega$-oxidation of the lactone to yield, 
after delactonisation, an $\alpha, \omega$-dicarboxylic acid. The production of such diacids by cells with defects in $\beta$ oxidation has already been described (Picataggio et al. 1992; Fabritius et al. 1998). This topic is of great interest to biotechnologists, as it enables the production of macrocyclic ketones of interest to the fragrance industry. However, with cells exhibiting an intact $\beta$-oxidation, this reaction can occur on the dicarboxylic acid, degrading it. Although Endrizzi-Joran (1994) did not see any differences in the degradation between uninduced and $\beta$ oxidation-induced cells, the involvement of $\beta$-oxidation in the degradation is highly suggested by our results with acyl-CoA oxidase-modified mutants (Waché et al. 2001): the mutant exhibiting no more $\beta$-oxidation is the only one unable to degrade $\gamma$-decalactone.

To avoid lactone degradation, some processes have proposed subtracting the lactone from the catabolism of yeast cells. This is presented later.

\section{Current developments}

Optimising the biotransformation

The main topic in the strategies to improve the $\gamma$ decalactone production yields concerns the $\beta$-oxidation pathway (Pagot et al. 1998; Waché et al. 1998, 2000a, 2001; Blin-Perrin et al. 2000).

As mentioned above, we modified the $\beta$-oxidation genotype in the yeast $Y$. lipolytica. Although the overexpression of the gene coding for thiolase did not modify $\gamma$ decalactone production (Pagot et al. 1998), $\beta$-oxidation enzymes appeared to be of the utmost importance in the biotransformation.

Two main problems have to be solved. First, $\beta$ oxidation can go on after the C10-level or can occur on $\gamma$ decalactone itself (Fig. 4). To resolve this point, works have been carried out to lower $\beta$-oxidation on the shortchain acyl-CoA (shorter than C10). In Y. lipolytica, the disruption of the short-chain-specific acyl-CoA oxidase (Aox3)-encoding gene (pox3) decreases lactone degradation during culture on $\mathrm{C} 18$ methyl ricinoleate substrate (Waché et al. 2000a, 2001). However, this disruption does not modify the degradation of $\mathrm{C} 10$ lactone substrate. This can be explained by the presence of two other non-chainlength-specific acyl-CoA oxidases (Aox4, Aox5). By disrupting the corresponding genes (pox4, pox5), one takes the risk of constructing a strain which is not very active, as the only active Aox remaining would be Aox2. We therefore constructed a strain disrupted for pox 2 , pox3 and pox 5 (which still possesses $P O X 4$, encoding a weakly active Aox) and with $P O X 2$ reincorporated in multicopies (Waché et al. 2002). The metabolism of this strain was slow, but no lactone degradation was observed. Since the Aox enzymes are targeted to peroxisomes as a heteropentamer possessing each Aox (Titorenko et al. 2002), the challenge would be to construct a strain possessing only the long-chain-specific Aox (Aox2) with good targeting.

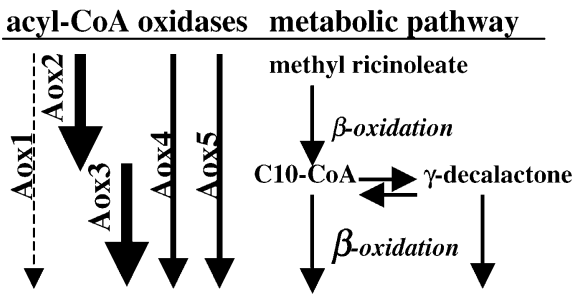

Fig. 4 Involvement of the five acyl-CoA oxidases (Aox1-5) of $Y$. lipolytica in the $\beta$-oxidation of ricinoleic acid and the degradation of $\gamma$-decalactone

The second problem is the modification of $\beta$-oxidation fluxes which can enable the switch between production of $\gamma$-decalactone and production of hydroxy-related lactones (Fig. 1). The yeast $Y$. lipolytica seems to have a low activity at the multifunctional enzyme level and this results in the accumulation of the three hydroxy-related lactones. It is therefore possible to decrease the Aox activity so that the first $\beta$-oxidation enzyme could increase its control on the pathway and $\gamma$-decalactone could accumulate more. This can be achieved with $\Delta$ pox $2 \Delta$ pox 3 mutants, as the corresponding Aox 2 Aox 3 enzymes are the more active ones and are required in targeting the global acyl-CoA oxidase to the peroxisome (Titorenko et al. 2002). With such mutants, the production of hydroxylactone is close to zero, whereas that of $\gamma$ decalactone goes on all along the culture (Waché et al. 2001).

It is also possible to modify the environmental conditions to change $\beta$-oxidation fluxes. For this goal, a recent study utilised the reducing agent dithiothreitol with a Sporidiobolus strain. Although the effect of this compound on the cell was not investigated, it resulted in a modification of $\gamma$-decalactone yield (Wang et al. 2000). Other environmental parameters can modify the biotransformation, probably by perturbing the equilibrium of $\beta$-oxidation fluxes. For instance, we investigated the influence of the biotransformation medium $\mathrm{pH}$. This can strongly influence lactone production by $Y$. lipolytica. It was observed that the $\gamma$-decalactone concentration in a medium containing phosphate buffer at $\mathrm{pH} 7$ was 3 -fold higher than that obtained in a non-buffered medium (Fig. 5). Gatfield et al. (1993) noted also a strong impact of the agitation parameter on the production of the various lactones.

\section{Lactone toxicity}

The high lactone concentrations (up to several grams per litre) produced by yeast cells may also be a limiting factor in industrial applications, since the metabolites become toxic towards the producing yeast (Feron et al. 1997). The decline in cell viability has been clearly associated with the increase in lactone concentration within culture media during biotransformation (Feron et al. 1997; Dufossé et al. 1999). Moreover, the antimicrobial properties of some 


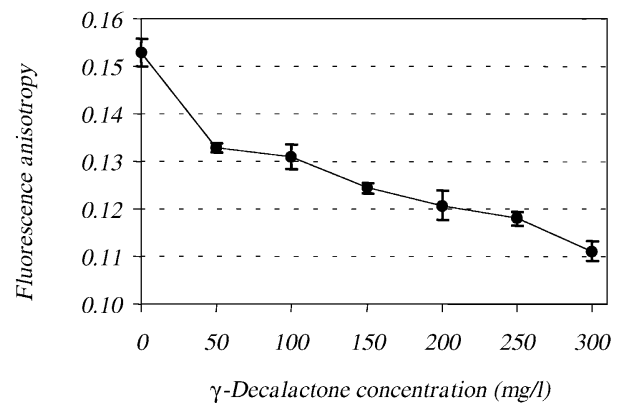

Fig. 5 Fluorescence anisotropy of $Y$. lipolytica cells determined in situ with the fluorescent probe 1,6-diphenyl-1,3,5-hexatriene, at $27{ }^{\circ} \mathrm{C}$ in the presence of $\gamma$-decalactone (adapted with permission from Aguedo et al. 2002a)

other lactones have been reported. For example, 2deceno- $\delta$-lactone, at a concentration of $100 \mathrm{mg} / \mathrm{l}$ inhibits the growth of bacteria (Nago et al. 1993). 6-Pentyl- $\alpha$ pyrone is toxic towards a producing strain of Trichoderma viride (Bonnarme et al. 1997); and $\gamma$-decalactone was reported to inhibit the growth of the producing yeast $S$. salmonicolor (Feron et al. 1996). Generally, microorganisms and animal cells (Adams et al. 1998) are able to withstand and, in many cases, to metabolise lactones up to a strain-dependent concentration threshold, beyond which these compounds become toxic (Feron et al. 1996).

Some mechanisms underlying lactone toxicity have been studied in our laboratory, using the yeast $Y$. lipolytica as a model. The growth of this yeast in a glucose-containing medium is inhibited by $\gamma$-decalactone at concentrations higher than $150 \mathrm{mg} / \mathrm{l}$. Such concentrations lead to a dissipation of membrane potential, as a consequence of the interaction of hydrophobic lactone with cell membranes. Infrared spectroscopic measurements revealed that increasing concentrations of the compound lowered the phase transition temperature of dimyristoylphosphatidylcholine films (Aguedo et al. 2002a) and in vivo fluorescence anisotropy measurements showed that yeast membrane fluidity is strongly increased (Fig. 6; Aguedo et al. 2002a). Interestingly, the data indicated also that, even for non-toxic concentrations of $\gamma$ decalactone, the membrane properties of $Y$. lipolytica were modified, due to the diffusion of lactone inside the phospholipid bilayers.

Some strategies have been developed to reduce lactone toxicity within the fermentation medium, as for example the addition into the culture media of inert oils (hydrogenated coconut oil or a mixture of tripalmitine, tristearine, triolein) or hydrophobic porous sorbents (Dufossé et al. 1997, 1999; Souchon et al. 1998). Such techniques enable the improvement of yeast viability, by trapping the hydrophobic lactones and so by decreasing their concentration within the aqueous phase. However, these techniques lower the biotransformation yields, probably by adsorbing part of the substrate. Another way of protecting yeast cells from lactone toxicity is the use of alginate beads to immobilise the micro-organism. Such a process

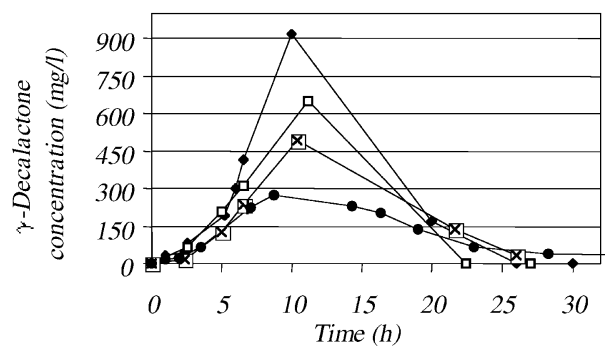

Fig. $6 \gamma$-Decalactone production in a non-buffered methyl ricinoleate medium $(10 \mathrm{~g} / 1$; black circles $)$, or in medium containing phosphate buffer $(0.1 \mathrm{M})$ at $\mathrm{pH} 7$ (black diamonds), or $\mathrm{pH} 8$ (white squares), or adjusted to $\mathrm{pH} 9$ with $\mathrm{NaOH}$ (squares containing crosses; all data from Aguedo 2002)

was investigated with Sporidiobolus sp. but did not notably improve the yields (Lee et al. 1999). So, according to these recent data concerning the interaction of lactones with the yeast membranes, new strategies may be tested within the culture medium to decrease the fluidising action of the metabolites. It should be possible to obtain such an effect, for example by lowering the process temperature or by adding membrane-stabilising agents to the culture medium (Beney and Gervais 2001).

Yeast behaviour within the biphasic medium

The biotransformation medium generally contains an important concentration of the precursor fatty acids and, once shaken in the presence of a surfactant, it forms an oil-in-water emulsion. It was previously reported that the size of lipid droplets (Bakhuis and Bos 1969), the inoculum and the cell concentration in the medium all influence the characteristics of an emulsion and the rate of yeast growth (Prokop et al. 1972). In the case of $\gamma$ decalactone production by $Y$. lipolytica, preliminary studies have been made concerning these points, as it appears important to better understand the uptake of the non-polar precursor, i.e. methyl ricinoleate. Thus, it was observed that in a medium containing $5 \mathrm{~g}$ methyl ricinoleate/l and inoculated with $Y$. lipolytica [optical density at $\left.600 \mathrm{~nm}\left(\mathrm{OD}_{600}\right)=0.25\right]$, the cells alone were sufficient to rapidly decrease the size of the lipid droplets (Waché et al. 2000b). The hypothesis of biosurfactant production was put forward, as Y. lipolytica was previously reported to release a bioemulsifier called liposan when grown in a hexadecane-containing medium (Cirigliano and Carman 1985). However, such a compound appears in the medium after several hours of culture, which is inconsistent with the observed immediate effect of the cells on the emulsion. So, cell-surface activity appeared to be an important factor in the yeast cell behaviour within the biotransformation medium. When the cell concentration is higher $\left(\mathrm{OD}_{600}=4.0\right)$ in a medium containing $10 \mathrm{~g}$ methyl ricinoleate/ 1 , the cells alone do not lead to lipid emulsification and the presence of a surfactant is necessary to improve the formation of small 
lipid droplets and thus lipid degradation by the cells. A direct contact occurs between the yeast cell surface and lipid droplets; and mainly numerous small-sized droplets adsorb onto the cell surface. So, the yeast surface properties are important in the interactions occurring between the emulsified substrate and the cells. These properties are currently being studied and it appears in fact that the adsorption of fatty globules to the yeast surface is linked to Lewis acid-base interactions, in part, rather than only to hydrophobic/hydrophilic interactions (Aguedo et al. 2003).

The cell release of biosurfactants and lipases into the medium may influence substrate assimilation by yeast cells. The excretion of such compounds during biotransformation is probable, although no data are available concerning these points. Y. lipolytica is able to excrete a biosurfactant (Cirigliano and Carman 1985) and also to produce high amounts of lipases (Pignède et al. 2000a, 2000b).

\section{Conclusion}

Several points are still to be studied, but the most important ones are probably concerning $\beta$-oxidation fluxes which can, by small environmental or genetic changes, greatly modify production yields. With the aim of studying this, an effort has to be made on the modelling of this complex pathway. Genetic constructions can also be improved, especially to get strains biotransforming more rapidly. Another field to investigate is the production of other lactones, a domain which is closely linked to the hydroxylation of the substrate.

The review of these data concerning the production of lactones shows that this field has an important impact on increasing our knowledge of lipid metabolism in yeast. The yeast $Y$. lipolytica, the object of this study, is, due to its great adaptation to hydrophobic environments, a very good model for lactone production. One great interest in this species is that it has become a model for many steps of non-polar substrate metabolism, such as the action of lipases, cytochrome P450, acyl-CoA oxidases and the biology of peroxisomes. The data existing at all these levels and the genome knowledge to come (Casaregola et al. 2000) will help to develop new applications for this unconventional yeast.

\section{References}

Adams TB, Greer DB, Doull J, Munro IC, Newberne P, Portoghese PS, Smith RL, Wagner BM, Weil CS, Woods IA, Ford RA (1998) The FEMA GRAS assessment of lactones used as flavour ingredients. Food Chem Toxicol 36:249-278

Aguedo M (2002) PhD thesis, ENSBANA, Université de Bourgogne, Dijon

Aguedo M, Waché Y, Belin J-M (2000) Biotransformation of ricinoleic acid into $\gamma$-decalactone by yeast cells: recent progress and current questions. Recent Res Dev Biotechnol Bioeng $3: 167-179$
Aguedo M, Beney L, Waché Y, Belin J-M (2002a) Mechanism underlying the toxicity of lactone aroma compounds towards the producing yeast cells. J Appl Microbiol (in press)

Aguedo M, Beney L, Waché Y, Belin J-M (2002b) Interaction of an odorant lactone with model phospholipid bilayers and its strong fluidizing action in yeast membrane. Int $\mathbf{J}$ Food Microbiol $80: 211-215$

Aguedo M, Waché Y, Mazoyer V, Sequeira-Le Grand A, Belin JM (2003) Increased electron-donor and electron-acceptor characters enhance the adhesion between oil droplets and cells of Yarrowia lipolytica as evaluated by a new cytometric assay. J Agric Food Chem (in press)

Ambid C, Carle S, De Billerbeck G (1999) Method for producing and extracting aromatic compounds. Int Patent WO9954432

Bakhuis E, Bos P (1969) Correlation between growth of Candida lipolytica and size of droplets in the hydrocarbon containing medium. Antonie Van Leeuwenhoek 35:F47-F48

Barth G, Gaillardin C (1996) The dimorphic fungus Yarrowia lipolytica. In: Wolf $\mathrm{K}$ (ed) Non-conventional yeasts in biotechnology. Springer, Berlin Heidelberg New York, pp 314-388

Barth G, Gaillardin C (1997) Physiology and genetics of the dimorphic fungus Yarrowia lipolytica. FEMS Microbiol Rev 19:219-237

Beney L, Gervais P (2001) Influence of the fluidity of the membrane on the response of microorganisms to environmental stresses. Appl Microbiol Biotechnol 57:34-42

Berger RG, Neuhäuser K, Drawert F (1986) Biosynthesis of flavor compounds by microorganisms. 6. Odorous constituents of Polyporus durus (Basidiomycetes). Z Naturforsch 41:963-970

Blin-Perrin C, Molle D, Dufossé L, Le-Quéré J-L, Viel C, Mauvais G, Feron G (2000) Metabolism of ricinoleic acid into $\gamma$ decalactone: $\beta$-oxidation and long chain acyl intermediates of ricinoleic acid in the genus Sporidiobolus sp. FEMS Microbiol Lett 188:69-74

Bonnarme P, Djian A, Latrasse A, Feron G, Giniès C, Durand A, Le Quéré J-L (1997) Production of 6-pentyl- $\alpha$-pyrone by Trichoderma sp. from vegetable oils. J Biotechnol 56:143-150

Bouchez-Naïtali M, Rakatozafy H, Marchal R, Leveau JY, Vandecasteele JP (1999) Diversity of bacterial strains degrading hexadecane in relation to the mode of substrate uptake. J Appl Microbiol 86:421-428

Bouchez-Naïtali M, Blanchet D, Bardin V, Vandecasteele JP (2001) Evidence for interfacial uptake in hexadecane degradation by Rhodococcus equi: the importance of cell flocculation. Microbiology 147:2537-2543

Brennan PJ, Lösel DM (1978) Physiology of fungal lipids: selected topics. In: Rose AH, Wilkinson JF (eds) Advances in microbial physiology, vol 17. Academic Press, London, pp 47-179

Cardillo R, Fronza G, Fuganti C, Grasselli P, Mele A, Pizzi D, Allegrone G, Barbeni M, Pisciotta A (1991a) Stereochemistry of the microbial generation of $\delta$-decanolide, $\gamma$-dodecanolide, and $\gamma$-nonanolide from C18 13-hydroxy, C18 10-hydroxy, and C19 14-hydroxy unsaturated fatty acids. J Org Chem 56:52375239

Cardillo R, Fuganti C, Barbeni M, Cabella P, Guerda PA, Allegrone $\mathrm{G}$ (1991b) Process for the microbiological production of $\gamma$ - and $\delta$-lactones. Eur Patent EP0412880

Casaregola S, Neuveglise C, Lepingle A, Bon E, Feynerol C, Artiguenave F, Wincker P, Gaillardin C (2000) Genomic exploration of the hemiascomycetous yeasts: 17. Yarrowia lipolytica. FEBS Lett 487:95-100

Cirigliano MC, Carman GM (1985) Purification and characterization of liposan, a bioemulsifier from Candida lipolytica. Appl Environ Microbiol 50:846-850

Collins RP, Halim AF (1972) Characterization of the major aroma constituent of the fungus Trichoderma viride. J Agric Food Chem 20:437-438

Dansen TB, Wirtz KW, Wanders RJ, Pap EH (2000) Peroxisomes in human fibroblasts have a basic $\mathrm{pH}$. Nat Cell Biol 2:51-53

Dell'Angelica EC, Stella CA, Ermàcora MA, Ramos EH, Santome JA (1992) Study on fatty acid binding by proteins in yeast. 
Dissimilar results in Saccharomyces cerevisiae and Yarrowia lipolytica. Comp Biochem Physiol 102B:261-265

Douma AC, Veenhuis M, Harder W (1987) A proton translocating ATPase is associated with the peroxisomal membrane of yeasts In: Fahimi HD, Sies H (eds) Peroxisomes in biology and medicine, Springer, Berlin Heidelberg New York, pp 199-204

Dufossé L (1993) Production de lactones par des levures appartenant au genre Sporidiobolus. PhD thesis, Université de Bourgogne, Dijon

Dufossé L, Latrasse A, Spinnler HE (1993) Importance des lactones dans les arômes alimentaires: structure, distribution, propriétés sensorielles. Sci Aliment 14:17-50

Dufossé L, Feron G, Latrasse A, Guichard E, Spinnler HE (1997) Chirality of the $\gamma$-lactones produced by Sporidiobolus salmonicolor grown in two different media. Chirality 9:667-671

Dufossé L, Souchon I, Feron G, Latrasse A, Spinnler HE, (1999) In situ detoxification of the fermentation medium during $\gamma$ decalactone production with the yeast Sporidiobolus salmonicolor. Biotechnol Prog 15:135-139

Elgersma Y, Roermund CW van, Wanders RJ, Tabak HF (1995) Peroxisomal and mitochondrial carnitine acetyltransferases of Saccharomyces cerevisiae are encoded by a single gene. EMBO J 14:3472-3479

Endrizzi A, Belin J-M (1995) Bioconversion of methyl ricinoleate to 4-hydroxy-decanoic acid and to $\gamma$-decalactone by yeasts of the genus Candida. J Basic Microbiol 35:285-292

Endrizzi A, Awadé AC, Belin J-M (1993) Presumptive involvement of methyl ricinoleate $\beta$-oxidation in the production of $\gamma$ decalactone by the yeast Pichia guilliermondii. FEMS Microbiol Lett 114:153-160

Endrizzi A, Pagot Y, Le Clainche A, Nicaud J-M, Belin J-M (1996) Production of lactones and peroxisomal $\beta$-oxidation in yeasts. Crit Rev Biotechnol 16:301-329

Endrizzi-Joran A (1994) PhD thesis, ENSBANA, Université de Bourgogne, Dijon

Ercoli B, Fuganti C, Grasselli P, Servi S, Allegrone G, Barbeni M (1992) Stereochemistry of the biogeneration of C-10 and C-12 $\gamma$-lactones in Yarrowia lipolytica and Pichia ohmeri. Biotechnol Lett 14:665-668

Fabritius D, Schäfer H-J, Steinbüchel A (1998) Bioconversion of sunflower oil, rapeseed oil and ricinoleic acid by Candida tropicalis M25. Appl Microbiol Biotechnol 50:573-578

Fantin G, Fogagnolo M, Guerrini A, Medici A, Pedrini P, Fontana S (2001) Enantioselective hydrolyses with Yarrowia lipolytica: a versatile strain for esters, enol esters, epoxides, and lactones. Tetrahedron 12:2709-2713

Farbood MI, Willis BJ (1983) Production of $\gamma$-decalactone. Int Patent WO8301072

Farbood MI, Morris JA, Sprecker MA, Bienkowski LJ, Miller KP, Vork MH, Hagedorn ML (1990) Process for preparing compositions containing unsaturated lactones, products produced thereby and organoleptic uses of said products. Eur Patent EP0354000

Farbood MI, Morris JA, McLean LB (1994) Fermentation process for preparing 10-hydroxy-C18-carboxylic acid and $\gamma$-dodecalactone derivatives. Eur Patent EP0578388

Feron G, Dufossé L, Pierard E, Bonnarme P, Le Quéré J-L, Spinnler HE (1996) Production, identification, and toxicity of $\gamma$-decalactone and 4-hydroxydecanoic acid from Sporidiobolus spp. Appl Environ Microbiol 62:2826-2831

Feron G, Dufossé L, Mauvais G, Bonnarme P, Spinnler HE (1997) Fatty acid accumulation in the yeast Sporidiobolus salmonicolor during batch production of $\gamma$-decalactone. FEMS Microbiol Lett 149:17-24

Fishbein W, Bessman S (1966) Purification and properties of an enzyme in human blood and rat liver microsomes catalyzing the formation and hydrolysis of $\gamma$-lactones. I. Tissue location, stoichiometry, specificity, distinction from esterase. J Biol Chem 241:4835-4841

Fuganti C, Servi S, Barbeni M, Cabella P (1993) New avenues in natural products: strategies in the biogeneration of flavors In:
Attar-ur-Rahman (ed) Studies in natural products chemistry. Elsevier, Amsterdam, pp 295-345

Gatfield IL (1999) Biotechnological production of natural flavor materials In: Teranishi R, Wick EL, Hornstein I (eds) Flavor chemistry, thirty years of progress. Kluwer, New York, pp 211227

Gatfield IL, Güntert M, Sommer H, Werkhoff P (1993) Some aspects of the microbiological production of flavor-active lactones with particular reference to $\gamma$-decalactone. Chem Mikrobiol Technol Lebensm 15:165-170

Gill CO, Hall MG, Ratledge C (1977) Lipid accumulation in an oleaginous yeast (Candida 107) growing in glucose in single state continuous culture. Appl Environ Microbiol 33:231-239

Gurvitz A, Mursula AM, Yagi AI, Hartig A, Ruis H, Rottensteiner $\mathrm{H}$, Hiltunen JK (1999) Alternatives to the isomerase dependent pathway for the $\beta$-oxidation of oleic acid are dispensable in Saccharomyces cerevisiae. J Biol Chem 274:24514-24521

Haffner T, Tressl R (1996) Biosynthesis of $(R)$ - $\gamma$-decanolactone in the yeast Sporobolomyces odorus. J Agric Food Chem 44:1218-1223

Hosaka K, Mishina M, Tanaka T, Kamiryo T, Numa S (1979) Acylcoenzyme-A synthetase I from Candida lipolytica. Purification, properties and immunochemical studies. Eur J Biochem 93:197-203

Iacazio G, Martini D, Faure B, N'Guyen MH (2002) Isolation and characterisation of 8-hydroxy-3Z,5Z-tetradecadienoic acid, a putative intermediate in Pichia guilliermondii $\gamma$-decalactone biosynthesis from ricinoleic acid. FEMS Microbiol Lett 209:55-60

Kalish JE, Chen CI, Gould SJ, Watkins PA (1995) Peroxisomal activation of long- and very long-chain fatty acids in the yeast Pichia pastoris. Biochem Biophys Res Commun 206:335-340

Knudsen J, Faergeman NJ, Skott H, Hummel R, Borsting C, Rose TM, Andersen JS, Hojrup P, Roepstorff P, Kristiansen K (1994) Yeast acyl-CoA-binding protein: acyl-CoA-binding affinity and effect on intracellular acyl-CoA pool size. Biochem J 302:479485

Knudsen J, Jensen MV, Hansen JK, Faergeman NJ, Neergaard TB, Gaigg B (1999) Role of acylCoA binding protein in acylCoA transport, metabolism and cell signaling. Mol Cell Biochem 192:95-103

Kohlwein SD, Paltauf F (1983) Uptake of fatty acids by the yeasts, Saccharomyces uvarum and Saccharomycopsis lipolytica. Biochim Biophys Acta 792:310-317

Lange H, Garbe LA (2000) Yeast $\alpha$-oxidation enzymes, used to degrade organic compounds by one carbon atom, used to convert 5-hydroxydecanoic acid to $\gamma$-nonalactone. Ger Patent DE19929577

Latrasse A, Guichard E, Piffaut C, Fournier N, Dufossé L (1993) Chirality of the $\gamma$-lactones formed by Fusarium poae INRA 45. Chirality 5:379-384

Lee S-L, Cheng H-Y, Chen W-C, Chou C-C (1999) Effect of physical factors on the production of $\gamma$-decalactone by immobilized cells of Sporidiobolus salmonicolor. Proc Biochem 34:845-850

Luo YS, Wang HJ, Gopalan KV, Srivastava DK, Nicaud JM, Chardot $\mathrm{T}$ (2000) Purification and characterization of the recombinant form of acyl-CoA oxidase 3 from the yeast Yarrowia lipolytica. Arch Biochem Biophys 384:1-8

Maga JA (1976) Lactones in food. Crit Rev Food Sci Nutr 8:1-56

Mandrup S, Jepsen R, Skott H, Rosendal J, Hojrup P, Kristiansen K, Knudsen J (1993) Effect of heterologous expression of acylCoA-binding protein on acyl-CoA level and composition in yeast. Biochem J 290:369-374

Medvedeva G, Meissel M, Volkova T (1969) Permeation of oleic acid into the yeast cell (a cytological study). Antonie van Leeuwenhoek 35:B27-B28

Meisel MN, Medvedeva GA, Kozlova TM (1976) Cytological mechanisms of the assimilation of $n$-alkanes by yeast. Mikrobiologiya 45:844-851

Meisel MN, Kozlova TM, Medvedeva GA, Novichkova AT, Pomoshchnikova NA, Seliverstova LA (1977) Yeast peroxi- 
somes, their development and functioning. Mikrobiologiya 46:835-845

Meyer J (1993) $\gamma$-Decalactone microbial production from alkyl ricinoleate by hydrolysis, $\beta$-oxidation, and chemical cyclisation of 4-hydroxy decanoic acid produced for flavouring and perfume. Ger Patent DE4126997

Mogensen IB, Schulenberg H, Hansen HO, Spener F, Knudsen J (1987) A novel acyl-CoA-binding protein from bovine liver. Effect on fatty acid synthesis. Biochem J 241:189-192

Nago H, Matsumoto M, Nakai S (1993) 2-Deceno- $\delta$-lactoneproducing fungi, strains of Fusarium solani, isolated by using medium containing decano- $\delta$-lactone as the sole carbon source. Biosci Biotechnol Biochem 57:2107-2110

Nicaud J-M, Belin J-M, Pagot Y, Endrizzi-Joran A (1996) Bioconversion of substrate with microbe auxotrophic for compound in medium deficient in this compound. Fr Patent FR2734843

Nicolay K, Veenhuis M, Douma AC, Harder W (1987) A ${ }^{31}$ P NMR study of the internal $\mathrm{pH}$ of yeast peroxisomes. Arch Microbiol 147:37-41

Okui S, Uchiyama M, Mizugaki M (1963a) Metabolism of hydroxy fatty acids. I. Metabolic conversion of ricinoleic acid by a certain microorganism to 8-D-(+)-hydroxy tetradec-cis-5-enoic acid. J Biochem (Tokyo) 53:265-270

Okui S, Uchiyama M, Mizugaki M (1963b) Metabolism of hydroxy fatty acids. II. Intermediates of the oxidative breakdown of ricinoleic acid by genus Candida. J Biochem (Tokyo) 54:536540

Okui S, Uchiyama M, Mizugaki M, Sugawara A (1963c) Characterization of hydroxy acids in depot fat after feeding of ricinoleic acid. Biochim Biophys Acta 70:344-346

Osumi M, Fukuzumi F, Yamada N, Nagatani T, Teranishi Y, Tanaka A, Fukui S (1975) Surface structure of some Candida yeast cells grown on $n$-alkanes. J Ferment Technol 53:244-248

Pagot Y (1997) PhD thesis, ENSBANA, Université de Bourgogne, Dijon

Pagot Y, Belin J-M (1996a) Fatty acid cellular metabolism and lactone production by the yeast Pichia guilliermondii. Appl Microbiol Biotechnol 45:349-354

Pagot Y, Belin J-M (1996b) Involvement of carnitine acyltransferases in peroxisomal fatty acid metabolism by the yeast Pichia guilliermondii. Appl Environ Microbiol 42:3864-3867

Pagot Y, Le Clainche A, Nicaud J-M, Waché Y, Belin J-M (1998) Peroxisomal $\beta$-oxidation activities and $\gamma$-decalactone production by the yeast Yarrowia lipolytica. Appl Microbiol Biotechnol 49:295-300

Palmieri L, Rottensteiner H, Girzalsky W, Scarcia P, Palmieri F, Erdmann R (2001) Identification and functional reconstitution of the yeast peroxisomal adenine nucleotide transporter. EMBO J 20:5049-5059

Picataggio S, Rohrer T, Deanda K, Lanning D, Reynolds R, Mielenz J, Eirich LD (1992) Metabolic engineering of Candida tropicalis for the production of long chain dicarboxylic acids. Bio/Technology 10:894-898

Pignède G, Wang H, Fudalej F, Seman M, Gaillardin C, Nicaud JM (2000a) Autocloning and amplification of LIP2 in Yarrowia lipolytica. Appl Environ Microbiol 66:3283-3289

Pignède G, Wang H, Fudalej F, Gaillardin C, Seman M, Nicaud JM (2000b) Characterization of an extracellular lipase encoded by LIP2 in Yarrowia lipolytica. J Bacteriol 182:2802-2810

Prokop A, Ludvik M, Erickson LE (1972) Growth models of cultures with two liquid phases. VIII. Experimental observations on droplet size and interfacial area. Biotechnol Bioeng 14:587-608

Rabenhorst J, Gatfield I (2000) Process for the production of $\gamma$ decalactone. Int Patent WO0024920

Sarris J, Latrasse A (1985) Production of odoriferous $\gamma$-lactones by Fusarium poae. Agric Biol Chem 49:3227-3230

Schjerling CK, Hummel R, Hansen JK, Borsting C, Mikkelsen JM, Kristiansen K, Knudsen J (1996) Disruption of the gene encoding the acyl-CoA-binding protein (ACB1) perturbs acyl-
CoA metabolism in Saccharomyces cerevisiae. J Biol Chem 271:22514-22521

Scholz H, Kohlwein SD, Paltauf F, Lezius A, Spener F (1990) Expression of a functionally active cardiac fatty acid-binding protein in the yeast Saccharomyces cerevisiae. Mol Cell Biochem 98:69-74

Smaczynska I, Skoneczny M, Kurlandzska A (1994) Studies on the effect of an heterologous fatty acid-binding protein on acylCoA oxidase induction in Saccharomyces cerevisiae. Biochem J 301:615-620

Souchon I, Spinnler HE, Dufossé L, Voilley A (1998) Trapping of $\gamma$-decalactone by adsorption on hydrophobic sorbents: application to the bioconversion of methyl ricinoleate by the yeast Sporidiobolus salmonicolor Biotechnol Tech 12:109-113

Spinnler HE, Giniès C, Khan JA, Vulfson EN (1996) Analysis of metabolic pathways by the growth of cells in the presence of organic solvents. Proc Natl Acad Sci USA 93:3373-3376

Tahara S, Fujiwara K, Ishizaka H, Mizutani J, Obata Y (1972) $\gamma$ Decalactone one of the constituents in cultured broth of Sporobolomyces odorus. Agric Biol Chem 36:2585-2587

Tanaka A, Fukui S (1989) Metabolism of $n$-alkanes In: Rose AH, Harrison JS (eds) The yeasts, vol 3. Academic Press, London, pp 261-287

Tang CS, Jennings WG (1968) Lactonic compounds of apricot. J Agric Food Chem 16:252-254

Titorenko VI, Nicaud JM, Wang H, Chan H, Rachubinski RA (2002) Acyl-CoA oxidase is imported as a heteropentameric, cofactor-containing complex into peroxisomes of Yarrowia lipolytica. J Cell Biol 156:481-494

Uchimaya M, Sato R, Mizugaki M (1963) Characterization of hydroxy acids in depot fat after feeding of ricinoleic acid. Biochim Biophys Acta 70:344

Van Roermund CW, Elgersma Y, Singh N, Wanders RJ, Tabak HF (1995) The membrane of peroxisomes in Saccharomyces cerevisiae is impermeable to $\mathrm{NAD}(\mathrm{H})$ and acetyl-CoA under in vivo conditions. EMBO J 14:3480-3486

Van Roermund CW, Drissen R, Van Den Berg M, Ijlst L, Hettema EH, Tabak HF, Waterham HR, Wanders RJ (2001) Identification of a peroxisomal ATP carrier required for medium-chain fatty acid $\beta$-oxidation and normal peroxisome proliferation in Saccharomyces cerevisiae. Mol Cell Biol 21:4321-4329

Van Veldhoven PP, Just WW, Mannaerts GP (1987) Permeability of the peroxisomal membrane to cofactors of $\beta$-oxidation. Evidence for the presence of a pore-forming protein. J Biol Chem 262:4310-4318

Voet D, Voet J (1990) Biochemistry. Wiley, New York

Waché Y, Pagot Y, Nicaud J-M, Belin J-M (1998) Acyl-CoA oxidase, a key step for lactone production by Yarrowia lipolytica. J Mol Catal B Enzym 149:165-169

Waché Y, Laroche C, Bergmark K, Møller-Andersen C, Aguedo M, Le Dall M-T, Wang H, Nicaud J-M, Belin J-M (2000a) Involvement of acyl-CoA oxidase isozymes in biotransformation of methyl ricinoleate into $\gamma$-decalactone by Yarrowia lipolytica. Appl Environ Microbiol 66:1233-1236

Waché Y, Bergmark K, Courthaudon J-L, Aguedo M, Nicaud J-M, Belin J-M (2000b) Medium-size droplets of methyl ricinoleate are reduced by cell-surface activity in the $\gamma$-decalactone production by Yarrowia lipolytica. Lett Appl Microbiol 30:183-187

Waché Y, Aguedo M, Choquet A, Gatfield I, Nicaud J-M, Belin J$\mathrm{M}$ (2001) Role of $\beta$-oxidation enzymes in the production of $\gamma$ decalactones from methyl ricinoleate. Appl Environ Microbiol 67:5700-5704

Waché Y, Aguedo M, LeDall M-T, Nicaud J-M, Belin J-M (2002) Optimization of Yarrowia lipolytica's $\beta$-oxidation pathway for lactones production. J Mol Catal B Enzym 153:347-351

Wang H, Le Clainche A, Le Dall M-T, Waché Y, Pagot Y, Belin JM, Gaillardin J-C, Nicaud J-M (1998) Cloning and characterization of the peroxisomal acyl CoA oxidase ACO3 gene from the alkane-utilizing yeast Yarrowia lipolytica. Yeast 14:13731386 
Wang H, Le Dall M-T, Waché Y, Laroche C, Belin J-M, Gaillardin J-C, Nicaud J-M (1999a) Evaluation of acyl coenzyme A oxidase (Aox) isozyme function in the $n$-alkane-assimilating yeast Yarrowia lipolytica. J Bacteriol 181:5140-5148

Wang H, Le Dall M-T, Waché Y, Laroche C, Belin J-M, Gaillardin J-C, Nicaud J-M (1999b) Cloning, sequencing, and characterization of five genes coding for acyl-CoA oxidase isozymes in the yeast Yarrowia lipolytica. Cell Biochem Biophys 31:165174
Wang X-D, Mauvais G, Cachon R, Diviès C, Feron G (2000) Addition of reducing agent dithiothreitol improves 4-decanolide synthesis by the genus Sporidiobolus. J Biosci Bioeng 90:338-340

Watkins PA, Lu JF, Steinberg SJ, Gould SJ, Smith KD, Braiterman LT (1998) Disruption of the Saccharomyces cerevisiae FAT1 gene decreases very long-chain fatty acyl-CoA synthetase activity and elevates intracellular very long-chain fatty acid concentrations. J Biol Chem 273:18210-18219 